\title{
Storms may disrupt top-down control of algal turf on fringing reefs
}

\author{
Hannah G. Hayes ${ }^{1} \cdot$ Pooneh S. Kalhori $^{1} \cdot$ Marcus Weiss $^{1} \cdot$ Shalanda R. Grier $^{1}$ • \\ Peggy Fong ${ }^{1}$ - Caitlin R. Fong ${ }^{2}$ (1)
}

Received: 21 September 2020/Accepted: 23 December 2020/Published online: 5 January 2021

(C) The Author(s), under exclusive licence to Springer-Verlag GmbH, DE part of Springer Nature 2021

\begin{abstract}
Storms strongly affect coral reefs; one unstudied but potentially important outcome may be a decrease in herbivory, presumably through changes to freshwater, sediment and nutrient influx. Algal turfs are sensitive early indicators of reef condition, and experimental evidence demonstrates low sediment loads and strong herbivory maintain short, healthy turf. While unknown, storms likely disrupt these controlling forces. We have observed storms that generate frequent, visible sediment plumes in Moorea, French Polynesia. To evaluate the effects of storms on herbivory, we conducted a set of field experiments manipulating herbivore access to naturally occurring turf under three rainfall regimes: no rain, light rain, and heavy rain that generated a plume event. We found strong effects of herbivores except following the storm, indicating disruption of typically strong top-down control by herbivores on algal turfs. Further research into the underlying mechanisms is critical as storm intensities and watershed development increase in many tropical regions.
\end{abstract}

Keywords Runoff · Sediment · Pulse events · Herbivory · Algal turf · Fringing reef

Topic Editor Andrew Hoey

Hannah G. Hayes, Pooneh S. Kalhori and Marcus Weiss: co-1st authorship.

Caitlin R. Fong

cat.r.fong@gmail.com

1 Department of Ecology and Evolutionary Biology, University of California, Los Angeles, USA

2 Department of Biology, California State University, Northridge, Los Angeles, USA

\section{Introduction}

Storms have strong effects on coral reefs, with the bestknown example being physical damage that often precedes transitions away from coral dominance (Connell 1997). One relatively unstudied but potentially important effect may be a decrease in herbivory, potentially through indirect effects like lowered salinity and increased sediment and nutrient influx. Discharge from rivers, streams, and estuaries is a main conduit of terrestrial anthropogenic impacts to coastal environments, and these inputs can be elevated by storm-driven runoff (Alongi 1998; Rabouille et al. 2001; Hyndes et al. 2014; den Haan et al. 2016; Fong et al. 2020a). In some cases, extreme rainfall events can generate episodic plumes that increase transport of sediment, leading to elevated levels of suspended sediment and nutrients to reef communities for over a week (den Haan et al. 2016; Fong et al. 2020a). Storm-generated runoff and subsequent transport of sediment in plume events may become more common because of global climate change and increased watershed development, motivating research on the effects of storms on nearshore tropical reef communities (IPCC 2019).

Herbivory is a critical ecological force supporting coral reef resilience through strong top-down control on algal communities like turf (McClanahan et al. 2003; Bellwood et al. 2004; Hughes et al. 2007). Short algal turfs are highly productive benthic space holders (Adey and Goertemiller 1987) that can transition to macroalgae or long turfs, depending on environmental conditions (Goatley et al. 2016; Muthukrishnan et al. 2016; Fong et al. 2020b). Generally, macroalgae is considered to be a degraded, undesirable state on coral reefs (e.g., Hughes et al. 2007). Turf, however, can be divided into short productive algal turf (SPATs) and long sediment-laden algal turf (LSATs) 
(sensu Goatley et al. 2016). SPATs are responsible for high levels of primary production in marine systems and provide critical food chain support (Goatley et al. 2016; Tebbett and Bellwood 2020). Coral can readily recruit to SPATs but not LSATs (Birrell et al. 2005), indicating maintenance of SPATs may be crucial to reef resilience. Strong topdown control is crucial to maintaining SPATs (e.g., Clausing et al. 2014, Fong et al. 2018) and all the services they provide, and disruption of this control may change benthic community composition, decreasing the resilience of reefs.

Storms may disrupt strong top-down control by herbivores on SPATs, and possibly mediate transitions to LSATs. One mechanism for this effect is increased fluxes of terrestrial sediment to nearshore environments, often via visible sediment plumes (Fong et al. 2020a, b). Sediment that settles on turf can disrupt strong top-down control by herbivores on SPATs, making it important to explore any potential relationship between storms and herbivory. Research has demonstrated that many herbivores avoid sediment-laden algal turf (Goatley \& Bellwood 2012; Clausing et al. 2014; Gordon et al. 2016; Tebbett et al. 2017a, 2017b). Since storms can drive plume events that enhance sediment transport (Fong et al. 2020a, b) and storms can increase sediment load (Goatley et al. 2016), release from herbivory pressure associated with rainfall, possibly mediated by sediment, may drive transitions to either LSATs or macroalgae.

To understand the short-term effects of storms on herbivory, we compared changes in turf height in plots exposed to herbivores and plots where herbivores were excluded. Experiments were conducted during no, light, and heavy rainfall events. These experiments occurred in different seasons and years, which may result in variance in initial heights and growth; therefore, in this study, we examine the effects of herbivory across these different baseline conditions of turf growth.

\section{Materials and methods}

To understand how rainfall events impact top-down control on short algal turf communities, we compared herbivore exclosure experiments from previously published experiments without rainfall (Fong et al. 2018) and with light rainfall (Fong et al. 2020b) to our experiment conducted during an extreme rainfall that produced a visible sediment plume in January 2020. All three of these experiments were conducted on the same fringing reef along Cook's Bay $(-17.489825,-149.825907)$ in Moorea, French Polynesia within the same $\sim 100 \mathrm{~m} \times 20 \mathrm{~m}$ area. In all three experiments, $15 \times 15 \mathrm{~cm}$ plots of $100 \%$ naturally occurring turf were manipulated. Experimental units were all fixed to dead coral heads. Plots were chosen haphazardly with the criteria that units were fixed to coral heads, $100 \%$ turf, and were $>1 \mathrm{~m}$ apart. To limit herbivory, half of the plots were caged with cylindrical hardware cloth barriers that had mesh openings of $1 \times 1 \mathrm{~cm}$. Uncaged plots were encircled with a three to five $\mathrm{cm}$ tall barrier to mark the edge of the plots while allowing access to herbivorous fishes. All plots had flaring bases where the mesh was folded outwards and contoured to the benthos to deter urchins from entering the plots, which limited herbivory in uncaged plots to fish alone. Very small fishes and invertebrates had access to all the cages, though prior work shows effects of their grazing were immeasurable (Fong et al. 2016). Barriers around uncaged plots did not reduce fish access in previous studies; further, both the full cage and rim have been shown to have minimal artifacts (see Clausing et al. 2014 for tests of cage effects). Turf height was measured using calibrated wire combs placed directly against the substrate and measured to the nearest $0.5 \mathrm{~mm}$ (details below).

Rainfall data for the previously published work were collected from the Moorea Long Term Ecological Research (LTER) website (Washburn and Brooks 2020). Data for rainfall in January-February 2020 (Experiment 3) were collected from a nearby airport. Travel restrictions due to COVID-19 limited the ability of the LTER to collect routine monitoring data, so these data are currently inaccessible. We averaged daily rainfall amounts across the total duration of each experiment (dates given below). For Experiment 3, we also noted the two days of intense storms where rainfall totals were maximal.

Our first dataset (Experiment 1) was subsetted from a larger experiment conducted during a period of no rainfall (Fong et al. 2018) that began on May 1, 2014 and concluded on May 16, 2014, lasting a total of 16 days. This portion of the experiment had 16 total replicates $(8$ caged and 8 uncaged), which were fastened at the tops of dead corals heads with $100 \%$ turf coverage and spaced a minimum of one meter apart. To estimate turf height, 10 independent height measurements were taken per plot, then averaged. We used measurements of turf height from the first and last days of the experimental manipulations (days 1 and 16) to calculate percent change in turf height per day.

Our second dataset (Experiment 2) was subsetted from a larger experiment conducted over a period of light rainfall, at an average of $1.1 \pm 0.52 \mathrm{~mm}$ per day. This portion of the experiment began April 28, 2017 and concluded May 29, 2017, lasting 32 days, and had 20 total replicate (10 uncaged and 10 caged) plots. To estimate turf height, five independent height measurements were taken per plot, then averaged; turf height was measured on days 1 and 32, and daily percent change in height calculated. Replication was reduced to 5 points because data from the previous 
experiment (Fong et al. 2018) indicated 5 measurements sufficiently captured variation in height within a plot and produced a stabilized mean.

Our third dataset (Experiment 3) comes from an experiment conducted January 25, 2020 to February 8, 2020, a total of 14 days. This experiment had 21 total replicates (13 caged and 8 uncaged) due to substantial loss in the field. We measured turf height at nine evenly spaced points per plot and took the average of these nine measurements; turf height was measured on days 1 and 14, and daily percent change in height calculated. On February 1 and 42020 heavy rainfall events of roughly 98 and $47 \mathrm{~mm}$, respectively, drove an influx of agricultural runoff creating a visual plume of red water originating at the mouth of the Pao Pao River; daily rainfall averaged $18.9 \pm 7.93 \mathrm{~mm}$ (Fig. 1). While we did not estimate sediment loads, comparable rainfall events have pulsed sediment into this bay (Fong et al. 2020a, b), and the water was visibly discolored with red sediment from the agricultural watershed (Fig. 1).

Turf height data was standardized across experiments as percent change per day and met assumptions of normality (Shapiro-Wilkes, $p=0.1315$ ) and homogeneity of variance (Levene test, $p=0.1451$ ) and were thus analyzed with a two-way ANOVA. Fixed effects were herbivory treatment (caged and uncaged) and experiment (1, 2, and 3).

\section{Results and discussion}

Overall, we found the effects of herbivory varied across our three experiments, with strong effects in Experiments 1 and 2 and no effect in Experiment 3, as evidenced by the significant interaction between herbivory and experiment (Table 1). In Experiment 1, turf grew almost 3 times faster in caged plots where herbivores were excluded than in open plots (Fig. 2a). In Experiment 2, turf in caged plots grew $\sim 5 \%$ per day while open plots did not grow (Fig. 2b). In Experiment 3, turf grew $>2 \%$ a day, with no effect of herbivory treatment (Fig. 2c).

Our results demonstrated that rainfall can disrupt strong biotic control on tropical reefs, possibly by modulating
Table 1 Results of a two-way ANOVA with herbivory treatment and experiment as fixed effects and daily percent change in turf height as the response

\begin{tabular}{lrrrr}
\hline & df & \multicolumn{1}{c}{ SS } & F value & $p$ value \\
\hline Herbivory & 1 & 1359.0 & 6.4332 & $\mathbf{0 . 0 1 4 4 4}$ \\
Experiment & 2 & 799.6 & 1.8926 & 0.16153 \\
Herbivory:Treatment & 2 & 1521.4 & 3.6009 & $\mathbf{0 . 0 3 4 7 5}$ \\
Residuals & 49 & $10,351.2$ & & \\
\hline
\end{tabular}

Bold indicates significant $(p<0.05)$ differences

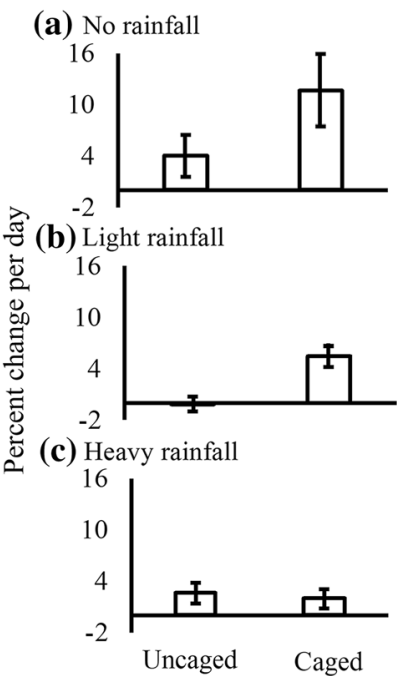

Fig.2 Daily change in turf height for treatments with full (Uncaged) and reduced (Caged) herbivore access during no rainfall (a), light rainfall (b), and heavy rainfall (c). Bars are means $\pm \mathrm{SE}$

abiotic conditions, which may be increasingly important in the Anthropocene. Global climate change will likely increase storm frequency and intensity in this region, which suggests storms that generate plume events will likely occur at higher frequencies and intensities (IPCC 2019). Following a heavy rainfall event, we observed a sediment plume, and we found that herbivory on SPATs was undetectable; this implies that rainfall generates plumes that can disrupt top-down control. Overall turf growth rate varied
Fig. 1 The photograph on the left is during a pre-rain day in Moorea taken at the docks at UC Berkeley Gump Station on January 22, 2020. The photograph on the right is at the same location, but on February 1,2020 , after heavy rainfall during one of the pulse events

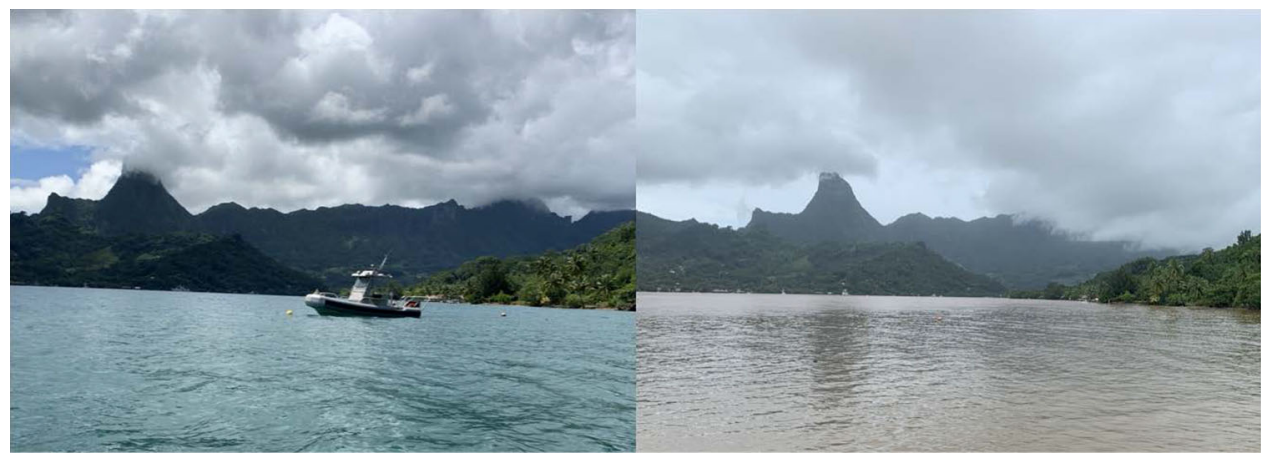


across the 3 experiments, which may have been driven by underlying variation in environmental conditions, such as seasonal changes in fish abundances and community structure as well as annual fluctuations. However, our significant interaction term was driven by a strong effect of caging out herbivores in experiments with no or little rain and no caging effect with heavy rain.

There are several possible mechanistic explanations for reduced top-down control associated with rainfall, including increased sediment load driven by plume formation and concurrent sediment transport. This explanation has strong support in the existing literature. For example, increased sedimentation may have deterred grazing by making turf unpalatable; research shows retention of fine sediments in algae discourages some herbivorous and detritivorous fishes (Rusuwa et al. 2006; Goatley and Bellwood 2012; Clausing et al. 2014; Gordon et al. 2016; Tebbett et al. 2017a, 2017b). Alternatively, herbivores may have left areas affected by the plume; some evidence demonstrates herbivores can relocate to avoid storm disturbance (Kaufman 1983; Walsh 1983) and enhanced sedimentation (Chew et al. 2013). Another possible explanation for rain disrupting herbivory may have been changes in temperature associated with rainfall and runoff; if rain brings colder water, this may have reduced herbivory by poikilothermic fishes (Smith 2008). Whatever the explanation, our data indicate top-down control, which is critical to support many ecosystem services provided by algal turf, may be suppressed by rainfall.

Even short-term reductions in herbivory associated with storms may drive shifts to long, sediment laden algal turfs, which provide reduced services. On an Australian reef, Severe Tropical Cyclone Yasi increased sediment loading and decreased herbivory, leading to longer algal turf that lasted for a few years after the storm (Goatley et al. 2016). Thus, these events have the potential to reshape communities. Short algal turfs are highly productive benthic community members and provide substantial trophic support (Aedy and Goertemiller 1987). However, increases in sediment can ultimately decrease turf productivity, reducing food chain support (Clausing et al. 2014; Tebbett and Bellwood 2020). Repeated storm events may therefore contribute to shifts toward algal dominated reefs that provide reduced services..

Predicted increase in precipitation tied directly to the global climate crisis indicates storms that generate plume events will likely occur at higher frequencies and intensities in some tropical regions (IPCC 2019). Our study shows these rainfall events can disrupt strong top-down control by herbivores, which may reshape benthic communities, highlighting the need for focused research on these events. Thus, it is vital to assess the potential for the wide-reaching effects of storms because these issues will likely become increasingly relevant in the coming years.

Acknowledgments We would like to thank UC Berkeley Gump Research Station for letting us use their facilities in Moorea. HGH, PSK, MW, SRG, and PF acknowledge support from the UCLA EEB Department. CRF acknowledges funding from National Science Foundation grant \#1612308.

\section{Compliance with ethical standards}

Conflict of interest On behalf of all authors, the corresponding author states that there is no conflict of interest.

\section{References}

Alongi DM (1998) Coastal ecosystem processes. CRC Press, Boca Raton, FL

Adey WH, Goertemiller T (1987) Coral reef algal turfs: master producers in nutrient poor seas. Phycologia 26:374-386

Bellwood DR, Hughes TP, Folke C, Nyström M (2004) Confronting the coral reef crisis. Nature 429(6994):827-833

Birrell CL, McCook LJ, Willis BL (2005) Effects of algal turfs and sediment on coral settlement. Mar Pollut Bull 51(1-4):408-414

Clausing RJ, Annunziata C, Baker G, Lee C, Bittick SJ, Fong P (2014) Effects of sediment depth on algal turf height are mediated by interactions with fish herbivory on a fringing reef. Mar Ecol Prog Ser 517:121-129

Connell JH (1997) Disturbance and recovery of coral assemblages. Coral Reefs 16:S101-S113

Den Haan J, Huisman J, Brocke HJ, Goehlich H, Latijnhouwers KR, Van Heeringen S, Honcoop SA, Bleyenberg TE, Schouten S, Cerli C, Hoitinga L (2016) Nitrogen and phosphorus uptake rates of different species from a coral reef community after a nutrient pulse. Sci Rep 6(1):1-3

Chew CA, Hepburn CD, Stephenson W (2013) Low-level sedimentation modifies behaviour in juvenile Haliotis iris and may affect their vulnerability to predation. Mar Biol 160:1213-1221

Fong P, Frazier NM, Thompkins-Cook C, Muthukrishnan R, Fong CR (2016) Size matters: experimental partitioning of the strength of fish herbivory on a fringing coral reef in Moorea, French Polynesia. Mar Ecol 37:933-942

Fong CR, Fong P (2018) Nutrient fluctuations in marine systems: press versus pulse nutrient subsidies affect producer competition and diversity in estuaries and coral reefs. Estuar Coasts 41:421-429

Fong CR, Gaynus CJ, Carpenter RC (2020a) Extreme rainfall events pulse substantial nutrients and sediments from terrestrial to nearshore coastal communities: a case study from French Polynesia. Sci Rep 10:2955

Fong CR, Gaynus CJ, Carpenter RC (2020b) Complex interactions among stressors evolve over time to drive shifts from short turfs to macroalgae on tropical reefs. Ecosphere 11:5

Goatley CHR, Bellwood DR (2012) Sediment suppresses herbivory across a coral reef depth gradient. Biol Lett 8:1016-1018

Goatley CHR, Bonaldo R, Fox R, Bellwood D (2016) Sediments and herbivory as sensitive indicators of coral reef degradation. Ecol Soc 21:21-29

Gordon SE, Goatley CHR, Bellwood DR (2016) Low-quality sediments deter grazing by the parrotfish Scarus rivulatus on inner-shelf reefs. Coral Reefs 35:285-291

Hughes TP, Rodrigues MJ, Bellwood DR, Ceccarelli D, HoeghGuldberg O, McCook L, Willis B (2007) Phase shifts, herbivory, 
and the resilience of coral reefs to climate change. Curr Biol 17:360-365

Hyndes GA, Nagelkerken I, McLeod RJ, Connolly RM, Lavery PS, Vanderklift MA (2014) Mechanisms and ecological role of carbon transfer within coastal seascapes. Biol Rev 89:232-254

IPCC, 2019: Summary for Policymakers. In: Pörtner HO, Roberts DC, Masson-Delmotte, Zhai VP, Tignor M, Poloczanska Mintenbeck EK, Alegría A, Nicolai M, Okem A, Petzold J, Rama B, Weyer NM (eds.) IPCC Special Report on the Ocean and Cryosphere in a Changing Climate. In press.

Kaufman LS (1983) Effects of Hurricane Allen on reef fish assemblages near Discovery Bay, Jamaica. Coral Reefs 2:43-47

Maina J, de Moel H, Vermaat JA, Bruggemann JH, Guillaume MMM, Grove CA, Madin JS, Mertz-Kraus R, Zinke J (2012) Linking coral river runoff proxies with climate variability, hydrology and land-use in Madagascar catchments. Mar Pollut Bull 64:2047-2059

McClanahan TR, Sala E, Stickels PA, Cokos BA, Baker AC, Starger CJ, Jones SH IV (2003) Interaction between nutrients and herbivory in controlling algal communities and coral condition on Glover's Reef, Belize. Mar Ecol Prog Ser 261:135-147

Muthukrishnan R, Lloyd-Smith JO, Fong P (2016) Mechanisms of resilience: empirically quantified positive feedbacks produce alternate stable states dynamics in a model of a tropical reef. J Ecol 104(6):1662-1672
Rabouille C, Mackenzie FT, Ver LM (2001) Influence of the human perturbation on carbon, nitrogen, and oxygen biogeochemical cycles in the global coastal ocean. Geochim Cosmochim Acta 65:3615-3641

Rusuwa B, Maruyama A, Yuma M (2006) Deterioration of cichlid habitat by increased sedimentation in the rocky littoral zone of Lake Malawi. Ichthyol Res 53:431-434

Smith TB (2008) Temperature effects on herbivory for an IndoPacific parrotfish in Panamá: implications for coral-algal competition. Coral Reefs 27(2):397-405

Tebbett SB, Goatley CHR, Bellwood DR (2017a) The effects of algal turf sediments and organic loads on feeding by coral reef surgeonfishes. PLoS ONE 12:e0169479

Tebbett SB, Goatley CHR, Bellwood DR (2017b) Fine sediments suppress detritivory on coral reefs. Mar Pollut Bull 114:934-940

Tebbett SB, Bellwood DR (2020) Sediments ratchet-down coral reef algal turf productivity. Sci Total Environ 713:136709

Walsh WJ (1983) Stability of a coral reef fish community following a catastrophic storm. Coral Reefs 2:49-63

Washburn, L and A. Brooks of Moorea Coral Reef LTER. 2020. MCR LTER: Coral Reef: Gump Station Meteorological Data, ongoing since 2006. knb-lter-mcr.9.45

Publisher's Note Springer Nature remains neutral with regard to jurisdictional claims in published maps and institutional affiliations. 